\title{
Effects of dietary supplementation of lipid-coated zinc oxide on intestinal mucosal morphology and expression of the genes associated with growth and immune function in weanling pigs
}

\author{
Young Min Song ${ }^{1}$, Myeong Hyeon Kim', Ha Na Kim², Insurk Jang ${ }^{2}$, Jeong Hee Han², \\ Giselle Ann Fontamillas ${ }^{4}$, Chul Young Lee ${ }^{1}$, and Byung-Chul Park ${ }^{4, *}$
}

\footnotetext{
* Corresponding Author: Byung-Chul Park Tel: +82-33-339-5792, Fax: +82-33-339-5763, E-mail: bcpark@snu.ac.kr

'Department of Animal Resources Technology, Gyeongnam National University of Science and Technology, Jinju 52725, Korea

2 Department of Animal Science and Biotechnology, Gyeongnam National University of Science and Technology, Jinju 52725, Korea

${ }^{3}$ College of Veterinary Medicine and Institute of Veterinary Science, Kangwon National University, Chuncheon 24341, Korea

${ }^{4}$ Graduate School of International Agricultural

Technology, and Institute of Green Bio Science and Technology, Seoul National University, Pyeongchang 25354, Korea
}

ORCID

Byung-Chul Park

https://orcid.org/0000-0003-1489-8678

Submitted Sept 28, 2017; Revised Nov 21, 2017; Accepted Dec 17, 2017
Objective: The present study was conducted to investigate the effects of a lipid-coated zinc oxide ( $\mathrm{ZnO}$ ) supplement Shield $\mathrm{Zn}(\mathrm{SZ})$ at the sub-pharmacological concentration on intestinal morphology and gene expression in weanling pigs, with an aim to gain insights into the mechanism of actions for SZ.

Methods: Forty 22-day-old weanling pigs were fed a nursery diet supplemented with 100 or $2,500 \mathrm{mg} \mathrm{Zn} / \mathrm{kg}$ with uncoated $\mathrm{ZnO}$ (negative control [NC] or positive control [PC], respectively), 100, 200, or $400 \mathrm{mg} \mathrm{Zn/kg} \mathrm{with} \mathrm{SZ} \mathrm{for} 14$ days and their intestinal tissues were taken for histological and molecular biological examinations. The villus height (VH) and crypt depth (CD) of the intestinal mucosa were measured microscopically following preparation of the tissue specimen; expression of the genes associated with growth and immune function was determined using the real-time quantitative polymerase chain reaction.

Results: There was no difference in daily gain, gain:feed, and diarrhea score between the SZ group and either of $\mathrm{NC}$ and $\mathrm{PC}$. The $\mathrm{VH}$ and $\mathrm{VH}: \mathrm{CD}$ ratio were less for the $\mathrm{SZ}$ group vs $\mathrm{NC}$ in the jejunum and duodenum, respectively $(\mathrm{p}<0.05)$. The jejunal mucosal mRNA levels of insulin-like growth factor (IGF-I) and interleukin (IL)-10 regressed and tended to regress $(\mathrm{p}=0.053)$ on the SZ concentration with a positive coefficient, respectively, whereas the IL-6 mRNA level regressed on the SZ concentration with a negative coefficient. The mRNA levels of IGF-I, zonula occludens protein-1, tumor necrosis factor- $\alpha$, IL-6, and IL-10 did not differ between the SZ group and either of $\mathrm{NC}$ and $\mathrm{PC}$; the occludin and transforming growth factor- $\beta 1 \mathrm{mRNA}$ levels were lower for the SZ group than for PC.

Conclusion: The present results are interpreted to suggest that dietary $\mathrm{ZnO}$ provided by SZ may play a role in intestinal mucosal growth and immune function by modulating the expression of $I G F-I, I L-6$, and $I L-10$ genes.

Keywords: Post-weaning Pig; Zinc Oxide; Intestine; Morphology; Gene Expression; Immunity

\section{INTRODUCTION}

Zinc oxide $(\mathrm{ZnO})$ is added to the nursery pig diet at 2,000 to $4,000 \mathrm{mg} / \mathrm{kg}$ to alleviate the diarrhea and growth check of the post-weaning piglets in many non-EU countries [1-3]. However, such a pharmacological $\mathrm{ZnO}$ supplementation poses a hazard of environmental pollution with the heavy metal, because dietary $\mathrm{ZnO}$ is mostly excreted in feces due to low absorption efficiency [4,5]. It is therefore necessary to find any Zn supplement that can elicit the effects of pharmacological $\mathrm{ZnO}$ at a lower dose. Shield $\mathrm{Zn}$ (SZ) used in the feeding trial of the present study is a proprietary $\mathrm{ZnO}$ product in which the mineral particle is coated with lipid to maximize the rate of delivery of the mineral in its native chemical form to the 
intestine without being ionized in the stomach.

The present $\mathrm{ZnO}$ study group has reported that dietary supplementation of $100 \mathrm{mg}$ Zn/kg with SZ ('basal SZ') had no beneficial effect on fecal consistency (diarrhea) score (FCS) and intestinal villus structure, with no or slightly growth-enhancing effect, compared with those with basal $\mathrm{ZnO}$ in weanling pigs whereas pharmacological $\mathrm{ZnO}(2,500 \mathrm{mg} \mathrm{Zn} / \mathrm{kg})$ increased the daily gain and reduced FCS without affecting the villus structure [6,7]. Moreover, the circulating and hepatic $\mathrm{Zn}$ concentrations of the piglets were greater in the pharmacological $\mathrm{ZnO}$ group than in the basal SZ and basal ZnO-100 groups, with no difference between the latter two groups, in these studies as well as in a latest study with post-weaning pigs challenged with enterotoxigenic Escherichia coli (ETEC) K88 (Han JH, unpublished results). The growth-enhancing effect of basal SZ observed in weanling piglets [7], as well as the growth-enhancing and diarrhea-alleviating effects of the supplementation in the ETEC K88-challenged piglets [8,9], are therefore likely to have resulted from the action of SZ in the intestine before its complete absorption into general circulation. Little is known, however, about the molecular mechanism of actions of SZ at the intestine as well as the dose effect of the $\mathrm{Zn}$ supplement. The present study was therefore performed to investigate the effects of SZ supplemented at the sub-pharmacological concentration compared with those with basal as well as pharmacological $\mathrm{ZnO}$ and also the dose effects of SZ on the intestinal mucosal morphology and expression of the genes associated with growth and immunity in weanling pigs and, thereby, to gain insights into the mechanism of actions of the $\mathrm{Zn}$ supplement.

\section{MATERIALS AND METHODS}

\section{Animals and dietary treatments}

The protocol for the present experiment was approved by the Institutional Animal Care and Use Committee of Gyeongnam National University of Science and Technology. Forty castrated piglets born to Duroc-sired Yorkshire $\times$ Landrace dams were allotted randomly to five dietary treatments in 40 pens, with eight pens per treatment, immediately after weaning at 21 days of age. The dietary treatments were supplementations to a basal nursery diet (Table 1) with $100 \mathrm{mg} \mathrm{Zn/kg} \mathrm{as} \mathrm{ZnO} \mathrm{(basal}$ $\mathrm{ZnO}$ or negative control [NC]), 2,500 mg Zn/kg as ZnO (pharmacological $\mathrm{ZnO}$ or positive control [PC]), 100, 200, or 400 mg Zn with Shield Zn (SZ-100, -200, or -400, respectively; CTCBIO, Seoul, Korea). The basal diet was formulated to meet or exceed the nutrient requirements for 5 to $10 \mathrm{~kg}$ piglets recommended by the Committee on Korean Feeding Standard for Swine [10]. The piglets were adapted to the experimental diet overnight and placed on a 14-day feeding trial on the following day. The diet and water were freely accessible to the piglets throughout the experiment. The ambient temperature
Table 1. Composition of the basal diet (as-fed basis)

\begin{tabular}{lc}
\hline Component & Content \\
\hline Ingredient (\%) & 33.16 \\
Corn & 8.0 \\
Barley & 10.0 \\
Soybean meal & 10.0 \\
Dehulled soybean meal & 4.15 \\
Fermented soybean & 12.56 \\
Sweet whey & 4.20 \\
Lactose & 5.00 \\
Fish meal & 3.00 \\
Wheat bran & 3.00 \\
Sugar & 3.00 \\
Soy oil & 0.70 \\
Organic acids & 0.30 \\
Limestone & 1.20 \\
Monocalcium phosphate & 0.30 \\
Salt & 0.15 \\
Vitamin premix) & 0.20 \\
Mineral premix & $($ Zn-free) \\
Others & \\
Total &
\end{tabular}

1) Provided per $\mathrm{kg}: 1,500 \mathrm{IU}$ vitamin $\mathrm{A} ; 2,000 \mathrm{IU}$ vitamin $\mathrm{D}_{3} ; 65 \mathrm{IU}$ vitamin $\mathrm{E} ; 1.5$ $\mathrm{mg}$ vitamin $\mathrm{K} ; 1.0 \mathrm{mg}$ thiamin; $6 \mathrm{mg}$ riboflavin; $20 \mathrm{mg}$ pantothenic acid; $25 \mathrm{mg}$ niacin; $1.5 \mathrm{mg}$ vitamin $\mathrm{B}_{6} ; 1 \mathrm{mg}$ folic acid; $25 \mu \mathrm{g}$ vitamin $\mathrm{B}^{12} ; 25 \mu \mathrm{g}$ biotin; and $150 \mathrm{mg}$ choline.

2) Provided per kg: 160 mg Cu; 200 mg Fe; 40 mg Mn; 1.0 mg l; 0.15 mg Co; and $0.4 \mathrm{mg} \mathrm{Se}$

3) Provided per total weight: $0.10 \%$ choline-HCl; $0.35 \%$ L-lysine- $\mathrm{HCl}(78 \%) ; 0.15 \%$ DL-methionine (99\%); 0.11\% L-threonine (99\%); 0.01\% L-tryptophan; and 0.05\% ethoxyquin.

4) Five experimental diets were supplemented to the basal diet with $125 \mathrm{mg} \mathrm{ZnO;}$ 3,125 mg ZnO; $139 \mathrm{mg}$ of $10 \%$ lipid (w/w)-coated ZnO (Shield Zn [SZ], CTCBIO,

Seoul); $278 \mathrm{mg} \mathrm{SZ}$; and $556 \mathrm{mg} \mathrm{SZ}$ per kg diet, respectively, as well as 0 to $0.30 \%$ corn, to provide $100,2,500,100,200$, and $400 \mathrm{mg} \mathrm{Zn/kg}$, respectively.

was controlled at $30^{\circ} \mathrm{C}$ and $29^{\circ} \mathrm{C}$ during the first and second weeks of the trial, respectively. The body weight and feed intake were measured on days 0,7 , and 14 and on days 7 and 14 , respectively. The fecal consistency was subjectively scored as previously described $[6,7]$ except that a 0 -to- 2 scale was used in the present study instead of the 1-to-3 scale: 0 , normal firm feces; 1 , soft feces; 2 , diarrhea.

\section{Histological examination}

All piglets were euthanized by electric stunning at the end of the feeding trial and the intestinal tissue was taken from each of the segments of the duodenum, jejunum, ileum, and colon also as described previously $[8,11,12]$. The tissue was fixed in a $10 \%$ neutral formalin solution, embedded, mounted onto the slide, and stained, after which the villus height $(\mathrm{VH})$ and 
crypt depth (CD) of each of the small intestinal segments, as well as the goblet cell density of the colon, were measured under the microscopic field.

\section{Real-time quantitative polymerase chain reaction}

Total RNA was extracted from the jejunal mucosa using RNAzol B (TRIzol Reagent, Invitrogen, Eugene, OR, USA). The levels of the target gene mRNA and the internal control $\beta$-actin gene were determined by real-time quantitative polymerase chain reaction (PCR) with SYBR Green Supermix (BioRad, Hercules, CA, USA) after the synthesis of the first-strand DNA using the cDNA Cycle kit (Invitrogen Co., Carlsbad, CA, USA) as previously described $[13,14]$. The nucleotide sequences of the forward and reverse primers for zonula occludens protein-1 (ZO-1) were 5'-CCTGAGTTTGATAGTGGCGTTGA-3' and 5'-AAATAGATTTCCTGCCCAATTCC-3', respectively; those for interleukin (IL)-10 were 5'-GCATCCACTTCCCAA CCA-3' and 5'-CTTCCTCATCTTCATCGTCAT-3', respectively. For the primers for insulin-like growth factor-I (IGF-I), occludin, IL- 6 , tumor necrosis factor- $\alpha$ (TNF)- $\alpha$, and transforming growth factor- $\beta 1$ (TGF- $\beta 1$ ), the nucleotide sequences designed by Shen et al [15] were used. The PCR conditions were initial denaturation at $95^{\circ} \mathrm{C}$ for $5 \mathrm{~min}, 40$ cycles of denaturation at $95^{\circ} \mathrm{C}$ for $15 \mathrm{~s}$, annealing at $60^{\circ} \mathrm{C}$ for $30 \mathrm{~s}$, and extension at $72^{\circ} \mathrm{C}$ for $30 \mathrm{~s}$. The relative level of the target gene expression was normalized to that for the control gene according to the $2^{-\Delta \Delta \mathrm{Ct}}$ method as described by Livak and Schmittgen [16].

\section{Statistical analysis}

The effects of the total SZ treatment (SZ-100, -200, and -400) compared with those of $\mathrm{NC}$ or PC were analyzed via contrast using the general linear model procedure of SAS (SAS Institute Inc., Cary, NC, USA). The piglet was the experimental unit in all variables. For the FCS, in which the model included the day and day $\times$ treatment interaction in addition to the treatment, the effects of the day and the day $\times$ treatment interaction were tested using day $\times$ piglet as the error term. The linear and quadratic regressions of each variable on the dietary SZ concentration within the total SZ treatment were analyzed using the regression procedure of SAS. The significance and tendency of the results of the regression and contrast were defined as $\mathrm{p}<0.05$ and $0.05 \leq \mathrm{p}<0.10$, respectively.

\section{RESULTS}

\section{Growth performance and FCS}

The average daily gain (ADG) did not differ between the SZ group and either of the $\mathrm{NC}$ and $\mathrm{PC}$ groups during the period of days 0 to 7,7 to 14 , or 0 to 14 (Table 2). The average daily feed intake, which did not differ between the SZ and NC groups for any of the experimental periods, tended to be less for the
SZ group vs PC during the period of days 7 to 14 and was also less for the former group for the entire 14-day period. On the other hand, the gain:feed ratio tended to be greater for the SZ group vs PC during the period of days 7 to 14 .

The majority of the animals exhibited a low FCS corresponding to the normal firm feces throughout the experiment. The FCS did not differ between the SZ group and either of the NC and PC groups on any of days 0,7 , and 14 or for the entire experimental period. Nevertheless, the mean FCS increased between days 0 and 7 and returned to the day- 0 level by day $14(0.10,0.30$, and 0.15 for days 0,7 , and 14 , respectively, with standard error of mean $=0.065$ ).

\section{Intestinal mucosal morphology}

The VH in the duodenum tended to be less for the SZ group vs $\mathrm{NC}$ whereas the $\mathrm{CD}$ was greater for the former (Table 3 ). The VH:CD ratio in the duodenum was less for the SZ group than for both $\mathrm{NC}$ and PC groups. In the jejunum, the VH was less for the SZ group vs NC group, but the $\mathrm{CD}$ and $\mathrm{VH}: \mathrm{CD}$ ratio did not differ between the SZ group vs either of the NC and $\mathrm{PC}$ groups. In the ileum, neither the $\mathrm{VH}$ nor $\mathrm{CD}$ differed between the SZ and either of the NC and PC groups, but the $\mathrm{VH}: \mathrm{CD}$ ratio tended to be less for the $\mathrm{SZ}$ group vs $\mathrm{ZnO}-100$. The goblet cell density in the colon did not differ between the SZ group and either of the NC and PC groups.

\section{Gene expression}

The IGF-I mRNA level in the jejunal mucosa did not differ between the SZ group and either of the NC and PC groups (Table 4). Within the SZ group, the IGF-I mRNA level regressed on the supplemental SZ concentration with a positive coefficient. The mRNA level of ZO-1 did not differ between the SZ group and either of the NC and PC groups. The occludin mRNA level for the SZ group did not differ from the level for the NC group, but it was lower than that for the PC group. The mRNA levels of TNF- $\alpha$, IL- 6 , and IL-10 did not differ between the SZ group and either of the NC and PC groups. Within the SZ group, the IL-6 mRNA level regressed on the supplemental SZ concentration with a negative coefficient whereas the IL-10 mRNA level tended to regress on the supplemental SZ concentration with a positive coefficient ( $\mathrm{p}=$ 0.053). The TGF- $\beta 1$ mRNA level did not differ between the $\mathrm{SZ}$ and NC groups, but it was lower for the SZ group vs PC.

\section{DISCUSSION}

The lack of any significant effect of the SZ treatment as well as PC vs NC on growth performance and FCS was consistent with the results observed by Jang et al [6] in which the piglets were housed in small 4-animal pens at the same farm where the present feeding trial was performed. However, these results differed from the increased ADG and decreased FCS in 
Table 2. Comparative effects of lipid-coated ZnO (Shield Zn [SZ]) vs uncoated ZnO on growth performance and fecal consistency of weanling pigs

\begin{tabular}{|c|c|c|c|c|c|c|c|c|c|c|}
\hline \multirow{3}{*}{ Variable } & \multicolumn{2}{|c|}{$\mathrm{ZnO}^{1)}$} & \multicolumn{3}{|c|}{$S Z^{1)}$} & \multirow{3}{*}{ SEM } & \multicolumn{4}{|c|}{$\mathrm{p}$-value } \\
\hline & \multirow{2}{*}{$\begin{array}{c}100 \\
\text { (NC) }\end{array}$} & \multirow{2}{*}{$\begin{array}{c}2,500 \\
(P C)\end{array}$} & \multirow[t]{2}{*}{100} & \multirow[t]{2}{*}{200} & \multirow[t]{2}{*}{400} & & \multicolumn{2}{|c|}{ Contrast } & \multicolumn{2}{|c|}{ Regression ${ }^{3)}$} \\
\hline & & & & & & & $\mathrm{NC}^{2)}$ & $\mathrm{PC}^{2)}$ & L & Q \\
\hline \multicolumn{11}{|l|}{ BW $(\mathrm{kg})$} \\
\hline Day 0 & 5.13 & 5.81 & 5.74 & 5.36 & 5.50 & 0.21 & 0.010 & 0.262 & 0.524 & 0.651 \\
\hline Day 7 & 6.22 & 7.26 & 6.97 & 6.89 & 6.47 & 0.30 & 0.113 & 0.171 & 0.162 & 0.154 \\
\hline Day 14 & 8.51 & 9.49 & 9.21 & 9.39 & 8.67 & 0.35 & 0.156 & 0.325 & 0.119 & 0.089 \\
\hline \multicolumn{11}{|l|}{$A D G(g)$} \\
\hline Days 0-7 & 156 & 207 & 175 & 219 & 138 & 25 & 0.456 & 0.315 & 0.138 & 0.079 \\
\hline Days 7-14 & 326 & 319 & 319 & 356 & 315 & 20 & 0.869 & 0.647 & 0.600 & 0.442 \\
\hline Overall & 241 & 263 & 247 & 288 & 226 & 17 & 0.529 & 0.651 & 0.147 & 0.070 \\
\hline \multicolumn{11}{|l|}{ ADFI (g) } \\
\hline Days 0-7 & 245 & 288 & 258 & 265 & 237 & 19 & 0.706 & 0.122 & 0.312 & 0.273 \\
\hline Days 7-14 & 599 & 689 & 592 & 652 & 574 & 35 & 0.867 & 0.051 & 0.470 & 0.340 \\
\hline Overall & 422 & 488 & 425 & 458 & 405 & 25 & 0.791 & 0.048 & 0.356 & 0.259 \\
\hline \multicolumn{11}{|l|}{ Gain:feed } \\
\hline Days 0-7 & 0.620 & 0.711 & 0.653 & 0.821 & 0.608 & 0.077 & 0.414 & 0.852 & 0.442 & 0.301 \\
\hline Days 7-14 & 0.546 & 0.473 & 0.547 & 0.559 & 0.559 & 0.040 & 0.849 & 0.081 & 0.862 & 0.882 \\
\hline Overall & 0.570 & 0.546 & 0.585 & 0.635 & 0.570 & 0.039 & 0.556 & 0.267 & 0.610 & 0.501 \\
\hline \multicolumn{11}{|l|}{$\mathrm{F}\left(S^{4)}\right.$} \\
\hline Day 0 & 0.13 & 0.25 & 0.00 & 0.00 & 0.13 & - & - & - & - & - \\
\hline Day 7 & 0.25 & 0.50 & 0.13 & 0.38 & 0.25 & $0.15^{5)}$ & - & - & - & - \\
\hline Day 14 & 0.25 & 0.13 & 0.13 & 0.13 & 0.13 & & - & - & - & - \\
\hline Overall ${ }^{6)}$ & 0.21 & 0.29 & 0.08 & 0.17 & 0.17 & 0.09 & 0.478 & 0.121 & 0.473 & 0.535 \\
\hline
\end{tabular}

NC, negative control; PC, positive control; SEM, standard error of mean; L, linear; Q, quadratic; BW, body weight; ADG, average daily gain; ADFI, average daily feed intake; FCS, fecal consistency score.

1) The numeral under the column heading indicates the dietary Zn concentration in $\mathrm{mg} / \mathrm{kg}$ provided by the Zn supplement. Data are the means of 8 piglets.

${ }^{2)}$ Total SZ (SZ-100, -200, and -400) vs NC and total SZ vs PC, respectively.

${ }^{3)}$ Linear and quadratic regressions on the dietary SZ concentration within the total SZ group piglets were analyzed separately.

4) Scored subjectively: 0, formal firm feces; 1 , soft feces; 2 , diarrhea.

${ }^{5)}$ Applies to all day $x$ treatment combinations.

${ }^{6)}$ The $p$ values for the day and day $\times$ treatment were 0.086 and 0.915 , respectively.

response to basal SZ in the piglets challenged with ETEC K88 $[8,9]$ as well as the increased ADG due to the treatment in unchallenged piglets in large pens (34 piglets/pen) under commercial setting [7]. It thus seems apparent from these results that the effects of the sub-pharmacological dose of SZ as well as pharmacological $\mathrm{ZnO}$ on growth performance and FCS in post-weaning pigs vary, depending on both the status of infection with ETEC and the pen size.

The VH/VH:CD ratio and CD are commonly used as positive and negative indices, respectively, for the structural integrity of the intestinal mucosa $[3,5,17]$. As such, the smaller or tendency of smaller VH or VH:CD ratio for the SZ group vs NC is suggestive of a negative effect of dietary $\mathrm{SZ}$ on the integrity of the villus structure. However, this may as well be taken as a tentative suggestion, because the $\mathrm{VH}$ or $\mathrm{VH}: \mathrm{CD}$ ratio occasionally decreased in response to a physiological dose of lipidcoated $\mathrm{ZnO}$ [6] or pharmacological $\mathrm{ZnO}$ ([18]; present study [the smaller ileal $\mathrm{VH}: \mathrm{CD}$ ratio for the $\mathrm{PC}$ vs $\mathrm{NC}$ group]), which commonly exhibited a positive or no effect on these structural variables $[8,9,19-21]$. Accordingly, for the present result of the SZ effect to be substantiated, it needs to be confirmed unequivocally in future studies.

Intestinal mucosal growth and immunity are known to be regulated by a number of growth factors [22,23], structural proteins [24], and cytokines [25-27]. Of those growth factors and structural proteins, IGF-I and the tight junction proteins ZO-1 and occludin play central roles in mucosal growth and the barrier function against the microbial dissemination, respectively. It is also well known that TNF- $\alpha$ and IL- 6 stimulate inflammatory responses whereas the anti-inflammatory cytokines TGF- $\beta 1$ and IL-10 suppress them $[28,29]$. The lower mRNA levels of occludin and TGF- $\beta 1$ for the SZ group vs PC observed in the present study then suggest that SZ-100 to -400 is less potent than pharmacological $\mathrm{ZnO}$ in inducing the expression of the structural protein and cytokine. Moreover, the regression and the tendency of regression of the IGF-I and IL-10 mRNA levels on the supplemental SZ concentration, respectively, suggest that the expression of these peptides may be up-regulated by SZ. Likewise, IL-6 expression is seemingly down-regulated by the increasing dose of SZ, as suggested by 
Table 3. Comparative effects of lipid-coated ZnO (Shield Zn [SZ]) vs uncoated ZnO on morphology of the gastrointestinal tract of weanling pigs

\begin{tabular}{|c|c|c|c|c|c|c|c|c|c|c|}
\hline \multirow{3}{*}{ Variable } & \multicolumn{2}{|c|}{$\mathrm{ZnO}^{1)}$} & \multicolumn{3}{|c|}{$S Z^{1)}$} & \multirow{3}{*}{ SEM } & \multicolumn{4}{|c|}{$\mathrm{p}$-value } \\
\hline & \multirow{2}{*}{$\begin{array}{c}100 \\
\text { (NC) }\end{array}$} & \multirow{2}{*}{$\begin{array}{c}2,500 \\
(P C)\end{array}$} & \multirow[t]{2}{*}{100} & \multirow[t]{2}{*}{200} & \multirow[t]{2}{*}{400} & & \multicolumn{2}{|c|}{ Contrast } & \multicolumn{2}{|c|}{ Regression $^{3)}$} \\
\hline & & & & & & & $N C^{2)}$ & $\mathrm{PC}^{2)}$ & $\mathbf{L}$ & Q \\
\hline \multicolumn{11}{|l|}{ Duodenum } \\
\hline $\mathrm{VH}(\mu \mathrm{m})$ & 302 & 280 & 280 & 272 & 278 & 11 & 0.056 & 0.813 & 0.948 & 0.983 \\
\hline$C D(\mu \mathrm{m})$ & 246 & 253 & 276 & 290 & 273 & 14 & 0.046 & 0.111 & 0.701 & 0.609 \\
\hline $\mathrm{VH}: \mathrm{CD}$ & 1.22 & 1.15 & 1.02 & 0.96 & 1.02 & 0.06 & 0.002 & 0.027 & 0.827 & 0.713 \\
\hline \multicolumn{11}{|l|}{ Jejunum } \\
\hline $\mathrm{VH}(\mu \mathrm{m})$ & 261 & 238 & 228 & 240 & 232 & 12 & 0.048 & 0.710 & 0.923 & 0.985 \\
\hline$C D(\mu m)$ & 206 & 191 & 184 & 199 & 191 & 11 & 0.218 & 0.986 & 0.777 & 0.889 \\
\hline $\mathrm{VH}: \mathrm{CD}$ & 1.27 & 1.28 & 1.25 & 1.22 & 1.22 & 0.07 & 0.558 & 0.501 & 0.960 & 0.791 \\
\hline \multicolumn{11}{|l|}{ Ileum } \\
\hline VH & 222 & 202 & 213 & 240 & 209 & 12 & 0.951 & 0.178 & 0.593 & 0.434 \\
\hline$C D$ & 163 & 170 & 175 & 190 & 167 & 11 & 0.282 & 0.597 & 0.411 & 0.312 \\
\hline $\mathrm{VH}: \mathrm{CD}$ & 1.39 & 1.20 & 1.21 & 1.29 & 1.26 & 0.06 & 0.074 & 0.451 & 0.744 & 0.833 \\
\hline \multicolumn{11}{|c|}{ Colon (cell density [cells $\left./ \mathrm{mm}^{2}\right]$ ) } \\
\hline Goblet cell & 956 & 980 & 920 & 962 & 819 & 69 & 0.490 & 0.325 & 0.314 & 0.271 \\
\hline
\end{tabular}

NC, negative control; PC, positive control; SEM, standard error of mean; L, linear; Q, quadratic; VH, villus height; CD, crypt depth.

1) The numeral under the column heading indicates the dietary Zn concentration in $\mathrm{mg} / \mathrm{kg}$ provided by the Zn supplement. Data are the means of 8 piglets.

${ }^{2)}$ Total SZ (SZ-100, -200, and -400) vs NC and total SZ vS. PC, respectively.

${ }^{3)}$ Linear and quadratic regressions on the dietary SZ concentration within the total SZ group piglets were analyzed separately.

the negative regression of its mRNA level on the supplemental SZ concentration. Shen et al [15] and Grilli et al [30] have reported the effects for one of two other lipid-coated $\mathrm{ZnO}$ supplements, respectively, on jejunal expression of a number of cytokines [30] as well as growth factors and tight junction proteins [15], but comparison of their results with the present ones was precluded because of the unknown efficacies of the different $\mathrm{Zn}$ supplements as well as different ranges of dietary concentrations of them examined in these and present studies.

Only limited information is available as to the effects of the lipid-coated $\mathrm{ZnO}$ supplement on expression of the genes in the intestine in association with its main function. Pharmacological $\mathrm{ZnO}$, however, is known to increase the intestinal expression of the genes of IGF-I, tight junction proteins, and anti-inflammatory cytokines [31-35], which has been interpreted to suggest that the $\mathrm{ZnO}$ supplementation improves the mucosal morphology and barrier function and also modulates the immune function. Shen et al [25] reported similar effects for a lipid-coated $\mathrm{ZnO}$ supplement, but such effects were apparent only within a certain range of supra-physiological concentrations. The present results also are thought to be similar to the suggested actions for pharmacological $\mathrm{ZnO}$; however, this was suggested by the regression or trend of the mRNA levels of the genes on the dietary SZ concentration rather than by the changes of the mRNA levels in response to $\mathrm{SZ}$ vs basal $\mathrm{ZnO}$, except for the results for occludin which

Table 4. Comparative effects of lipid-coated ZnO (Shield Zn [SZ]) vs uncoated ZnO on gene expressions in the jejunal mucosa of weanling pigs

\begin{tabular}{|c|c|c|c|c|c|c|c|c|c|c|}
\hline \multirow{3}{*}{ Variable } & \multicolumn{2}{|c|}{$\mathrm{ZnO}^{1)}$} & \multicolumn{3}{|c|}{$\mathrm{SZ}^{1)}$} & \multirow{3}{*}{ SEM } & \multicolumn{4}{|c|}{$p$-value } \\
\hline & \multirow{2}{*}{$\begin{array}{c}100 \\
\text { (NC) }\end{array}$} & \multirow{2}{*}{$\begin{array}{c}2,500 \\
(P C)\end{array}$} & \multirow[t]{2}{*}{100} & \multirow[t]{2}{*}{200} & \multirow[t]{2}{*}{400} & & \multicolumn{2}{|c|}{ Contrast } & \multicolumn{2}{|c|}{ Regression ${ }^{3)}$} \\
\hline & & & & & & & $N C^{2)}$ & $\mathrm{PC}^{2)}$ & L & $Q$ \\
\hline IGF-I & 1.00 & 2.09 & 0.58 & 1.27 & 2.21 & 0.54 & 0.572 & 0.248 & 0.003 & 0.004 \\
\hline ZO-1 & 1.00 & 3.59 & 1.16 & 2.03 & 3.01 & 1.39 & 0.511 & 0.351 & 0.142 & 0.157 \\
\hline Occludin & 1.00 & 1.99 & 0.95 & 0.53 & 0.72 & 0.39 & 0.562 & 0.009 & 0.605 & 0.743 \\
\hline$T N F-\alpha$ & 1.00 & 1.70 & 0.39 & 1.17 & 1.33 & 0.56 & 0.951 & 0.261 & 0.163 & 0.210 \\
\hline IL-6 & 1.00 & 1.28 & 2.31 & 0.99 & 0.65 & 0.38 & 0.477 & 0.929 & 0.017 & 0.033 \\
\hline IL-10 & 1.00 & 2.87 & 0.37 & 1.12 & 1.92 & 0.99 & 0.906 & 0.141 & 0.053 & 0.062 \\
\hline TGF- $\beta 1$ & 1.00 & 2.52 & 0.87 & 1.07 & 1.47 & 0.36 & 0.740 & 0.002 & 0.119 & 0.123 \\
\hline
\end{tabular}

NC, negative control; PC, positive control; SEM, standard error of mean; L, linear; Q, quadratic; IGF-I, insulin-like growth factor-l; ZO-1, zonula occludens protein-1; TNF- $\alpha$, tumor necrosis factor- $\alpha$; IL-6, interleukin-6; TGF- $\beta 1$, transforming growth factor- $\beta 1$.

1) The numeral under the column heading indicates the dietary Zn concentration in $\mathrm{mg} / \mathrm{kg}$ provided by the $\mathrm{Zn}$ supplement. Data are the means of 8 piglets.

${ }^{2)}$ Total SZ (SZ-100, -200, and -400) vs. NC and total SZ vs PC, respectively.

3) Linear and quadratic regressions on the dietary SZ concentration within the total SZ group piglets were analyzed separately. 
exhibited no trend of the dose-responsiveness. Obviously, however, more studies are necessary to work out the dose effects of SZ on intestinal expression of the genes as related to growth and mucosal barrier function and immunity.

Collectively, the results of the present study are suggestive of the following conclusions. Dietary supplementation with neither the sub-pharmacological dose of SZ nor pharmacological $\mathrm{ZnO}$ has any significant effect on growth performance or FCS for weanling pigs when the piglets are housed individually. Dietary SZ may cause a decrease in VH or VH:CD ratio of the small intestine, which needs to be confirmed in future studies. Finally, dietary SZ may play a role in growth and inflammatory responses of the intestinal mucosa by modulating the expression of IGF-I, IL-6, and IL-10 genes in postweaning pigs.

\section{CONFLICT OF INTEREST}

We certify that there is no conflict of interest with any financial organization regarding the material discussed in the manuscript.

\section{ACKNOWLEDGMENTS}

This work was supported by the Research Grant 2017 of Gyeongnam National University of Science and Technology. The authors thank Dr. Man Jong Park, Mr. Man Hee Ha, and Mr. Kyung Soon Jang for their assistance with the feeding trial.

\section{REFERENCES}

1. Hill GM, Mahan DC, Carter SD, et al. Effect of pharmacological concentrations of zinc oxide with or without the inclusion of an antibacterial agent on nursery pig performance. J Anim Sci 2001;79:934-41.

2. Heo JM, Opapeju FO, Pluske JR, et al. Gastrointestinal health and function in weaned pigs: a review of feeding strategies to control post-weaning diarrhoea without using in-feed antimicrobial compounds. J Anim Physiol Anim Nutr 2013;97:20737.

3. Adewole DI, Kim IH, Nyachoti CM. Gut health of pigs: challenge models and response criteria with a critical analysis of the effectiveness of selected feed additives - a review. AsianAustralas J Anim Sci 2016;29:909-24.

4. Pekas JC. Zinc 65 metabolism: gastrointestinal secretion by the pig. Am J Physiol 1966;211:407-13.

5. Hill GM. Minerals and mineral utilization in swine. In: Chiba LI, editor. Sustainable swine nutrition. Oxford, UK: John Wiley \& Sons, Inc.; 2013. p. 173-95.

6. Jang I, Kwon CH, Ha DM, et al. Effects of a lipid-encapsulated zinc oxide supplement on growth performance and intestinal morphology and digestive enzyme activities in weanling pigs.
J Anim Sci Technol 2014;56:29.

7. Park BC, Jung DY, Kang SY, et al. Effects of dietary supplementation of a zinc oxide product encapsulated with lipid on growth performance, intestinal morphology, and digestive enzyme activities in weanling pigs. Anim Feed Sci Technol 2015;200: 112-7.

8. Kwon CH, Lee CY, Han SY, et al. Effects of dietary supplementation of lipid-encapsulated zinc oxide on colibacillosis, growth and intestinal morphology in weaned piglets challenged with enterotoxigenic Escherichia coli. Anim Sci J 2014;85:805-13.

9. Kim SJ, Kwon CH, Park BC, et al. Effects of a lipid-encapsulated zinc oxide dietary supplement on growth parameters and intestinal morphology in weanling pigs artifically infected with enterotoxigenic Escherichia coli. J Anim Sci Technol 2015;57:4.

10. Committee on Korean Feeding Standard for Swine, National Institute of Animal Science, Rural Development Administration. Korean feeding standard for swine. 2nd ed. Suwon, Korea: Sangrock Press; 2007.

11. Lee CY, Lim JW, Ko YH, et al. Intestinal growth and deveopment of weanling pigs in response to dietary supplementation of antibiotics, phytogenic products and brewer's yeast plus Bacillus spores. Anim Feed Sci Technol 2011:53:227-35.

12. Lee CY, Kim SJ, Park BC, et al. Effects of dietary supplementation of bacteriophages against enterotoxigenic Escherichia coli (ETEC) K88 on clinical symptoms of post-weaning pigs challenged with the ETEC pathogen. J Anim Physiol Anim Nutr 2017;101:88-95.

13. Park JG, An YS, Sohn SH, et al. The effects of dietary supplementation of vitamin $\mathrm{C}$ or $\mathrm{E}$ on the expressions of endoplasmic reticulum stress, lipid and glucose metabolism associated genes in broiler chickens. Korean J Poult Sci 2013;40:147-55.

14. Jang IS, Ko YH, Moon YS, et al. Effects of vitamin C or E on the pro-inflammaory cytokines, heat shock protein 70 and antioxidant status in broiler chicks under summer conditions. Asian-Australas J Anim Sci 2014;27:749-56.

15. Shen J, Chen Y, Wang Z, et al. Coated zinc oxide improves intestinal immunity function and regulates microbiota composition in weaned piglets. Br J Nutr 2014;111:2123-34.

16. Livak KJ, Schmittgen TD. Analysis of relative gene expression data using real-time quantitative PCR and the 2(-Delta Delta C(T)) method. Methods 2001;25:402-8.

17. Nabuur MJ. Weaning piglets as a model for studying pathophysiology of diarrhea. Vet Q 1998;20 (Suppl 3):S42-5.

18. Hedemann MS, Jensen BB, Poulsen HD. Influence of dietary zinc and copper on digestive enzyme activity and intestinal morphology in weaned pigs. J Anim Sci 2006;84:3310-20.

19. Owusu-Asiedu A, Nyachoti CM, Marquardt RR. Response of early-weaned pigs to an enterotoxigenic Escherichia coli (K88) challenge when fed diets containing spray-dried porcine plasma or pea protein isolate plus egg yolk antibody, zinc oxide, fumaric acid, or antibiotic. J Anim Sci 2003;81:1790-8. 
20. Slade RD, Kyriazakis I, Carroll SM, et al. Effect of rearing environment and dietary zinc oxide on the response of grouphoused weaned pigs to enterotoxigenic Escherchia coli O149 challenge. Animal 2011;5:1170-8.

21. Liu P, Pieper R, Tedin L, et al. Effect of dietary zinc oxide on jejunal morphological and immunological characteristics in weaned piglets. J Anim Sci 2014;92:5009-18.

22. Dignass AU, Sturn A. Peptide growth factors in the intestine. Eur J Gastroenterol Hepatol 2001;3:763-70.

23. Bortvedt SF, Lund PK. Insulin-like growth factor 1: common mediator of multiple enterotrophic hormones and growth factors. Curr Opin Gastroenterol 2012;28:89-98.

24. Castoldi A, Favero de Aguiar C, Moraes-Vieira PM, et al. They must hold tight: junction proteins, microbiota and immunity in intestinal mucosa. Curr Protein Pept Sci 2015;16:655-71.

25. Winter SE, Keestra AM, Tsolis RM, et al. The blessings and curses of intestinal inflammation. Cell Host Microbe 2010;8: 36-43.

26. Willing BP, Malik G, Van Kessel AG. Nutrition and gut health. In: Chiba LI, editor. Sustainable swine nutrition. Oxford, UK: John Wiley \& Sons, Inc.; 2013. p. 197-213.

27. Bamias G, Arseneau KO, Cominelli F. Cytokines and mucosal immunity. Curr Opin Gastroenterol 2014;30:547-52.

28. Oberholzer A, Oberholzer C, Moldawer LL. Interleukin-10: a complex role in the pathogenesis of sepsis syndromes and its potential as an anti-inflammatory drug. Crit Care Med 2002; 30(Suppl 1):558-63.
29. Ruemmele FM, Garnier-Lenglinë $\mathrm{H}$. Transforming growth factor and intestinal inflammation: the role of nutrition. Nestle Nutr Inst Workshop Ser 2013;77:91-8.

30. Grilli E, Tugnoli B, Vitari F, et al. Low doses of micro-encapsulated zinc oxide improve performance and modulate the ileum architecture, inflammatory cytokines and tight junctions expression of weaned pigs. Animal 2015;9:1760-8.

31. Hu C, Song J, Li Y, et al. Diosmectite-zinc oxide composite improves intestinal barrier function, modulates expression of pro-inflammatory cytokines and tight junction protein in early weaned pigs. Br J Nutr 2013;110:681-8.

32. Song ZH, Xiao K, Ke YL, et al. Zinc oxide influences mitogenactivated protein kinase and TGF- $\beta 1$ signaling pathways, and enhances intestinal barrier integrity in weaned pigs. Innate Immun 2014;21:342-8.

33. Li X, Yin J, Li D, et al. Dietary supplementation with zinc oxide increases Igf-I and Igf-I receptor gene expression in the small intestine of weanling piglets. J Nutr 2006;136:1786-91.

34. Zhang B, Guo Y. Supplemental zinc reduced intestinal permeability by enhancing occludin and zonula occludens protein-1 (ZO-1) expression in weanling piglets. Br J Nutr 2009;102: 686-93.

35. Wang C, Xie P, Liu LL, et al. Use of lower level of capsulated zinc oxide as an alternative to pharmacological dose of zinc oxide for weaned piglets. Asian J Anim Vet Adv 2012;7:1290300 . 